\title{
Adapting to climate change: using urban renewal in managing long-term flood risk
}

\author{
C. Zevenbergen ${ }^{1,2,3}$, W. Veerbeek ${ }^{1}$, B. Gersonius ${ }^{2}$, J. Thepen ${ }^{3}$ \\ \& S. van Herk ${ }^{3}$ \\ ${ }^{I}$ Dura Vermeer Business Development BV, Hoofddorp, The Netherlands \\ ${ }^{2}$ UNESCO-IHE, Delft, The Netherlands \\ ${ }^{3}$ Technical University, Delft, The Netherlands
}

\begin{abstract}
Cities are dynamic systems. Understanding the role of time and the way it shapes the urban fabric and structure is crucial to assess urban flood vulnerability and to manage the capacity of cities to adapt to changes in demography as well as in climatic conditions. Consequently, cities have to learn from the past and anticipate the future in order to develop and implement effective flood management approaches. They have to eliminate unsatisfactory practices through investigation, experimentation and evaluation. Urban renewal of buildings and infrastructure is one of the means by which cities adapt to long term changes, to correct old errors and to increase flood resilience. According to the latest climate change scenarios flood frequency is going to increase significantly over the lifetime of existing buildings. Therefore, the inclusion of pro-active retrofitting in regular urban renewal schemes and decreasing lifetime cycles of new buildings are likely sound and effective strategies to increase the robustness of the urban fabric to climate change. Since current building practices are based upon the assumption that the built environment will not experience significant change, these approaches will have major ramifications for investment levels and building methods. In order to account for the relatively rapid rate of substitution of buildings and other built structures it is argued in this paper that the life cycle assessment and full cost accounting of the building stock should be included in the development of effective UFM strategies.
\end{abstract}

Keywords: floods, climate change, adaptation, resilience, urbanisation, longterm planning, flood proofing, pro-active retrofitting. 


\section{Introduction}

With approximately $75 \%$ of its population living in urban areas, Europe is one of the most urbanized continents on earth. Floods are the most common natural disaster in Europe and in terms of economic damage, the most costly ones [1,2]. Urbanization and climate change are the major pressures inducing or intensifying floods and their impacts. Long-term thinking is a prerequisite for addressing these changes and associated uncertainties. However, in conventional urban planning a 20-years horizon is considered long-term and consequently most urban flood assessments focus on the consequences under static conditions of climate and building stock. In recent years there has been a growing recognition that urban flood management policies should consider the implications of these changes $[3,4]$. For example, the new Flood Directive regulation asks for dealing with foreseeable future changes of flood risks in the long term including climate change and societal changes [5].

Planning ahead opens the way to develop strategies that are more resilient, adaptable and responsive. In Europe, the building stock is mainly aging and there is much heritage. European dwellings have a typical lifetime of about 50 years (USA closer to 35 and Japan to 15 years), while in many flood prone areas all over the world continuous restructuring is common practice. Many European cities are composed of mixtures of buildings of different ages and life spans, but within 30 years, some one third of it's building stock will be renewed [6]. These (re)development projects may provide a window of opportunity to make adjustments in the process of urban renewal and to adapt to new conditions such as increased flood risk.

\section{Need for long-term planning}

Long-term thinking calls for a new attitude. An attitude where we look beyond short-term constraints and opportunities and focus on the long-term planning horizon. One of the few studies in the field of flood risk management with a long-term perspective is OST Foresight Future Flooding [7]. This study involves a national assessment of the changes in future flood risk and effectiveness of responses for a range of climate change and socio-economic scenario's in the UK. Based on these results the Association of British Insures has estimated that the costs of flooding in the South East could be more that 80 million euro each year if steps to manage potential losses are not undertaken [8]. This figure could increase tenfold once climate change effects are felt in full. There is no doubt that the long-term challenges caused by climate change will act as a catalyst to "mainstreaming" adaptation measures into existing decision-making processes. Adapting to climate change, however, is typically a local action and the findings of national or even regional climate scenario's and vulnerability assessments have to be downscaled to assess local potential consequences and to identify adequate responses $[9,10]$.

One of the challenges of assessing cities vulnerability to climate change is the complex and dynamic nature of the building stock. Neighbourhoods, buildings 
and their components are heterogeneous in their composition. Therefore high resolution data are needed to accurately assess potential flood impacts. Moreover, buildings are closely connected and integrated with other attributes in the building environment and their function as well as their physical properties may change over time. Consequently, in order to understand local impacts and their temporal changes downscaling and tailoring of existing assessment models are required that recognize the dynamic behaviour of the individual attributes of the urban fabric. Recently Veerbeek et al. [11] conducted a detailed flood damage assessment study for the city of Dordrecht using a damage assessment model on a much higher level of detail $(10 \times 10 \mathrm{~m}$ grid) than used in conventional urban flood risk assessments. These high resolution analyses revealed large differentiation in spatial and temporal distributions of expected flood damages as a function of different climate scenario's and gave important clues to identifying local adaptive responses that have the potential of becoming 'mainstream' in other decision-making processes such as substitution rates of buildings and built components.

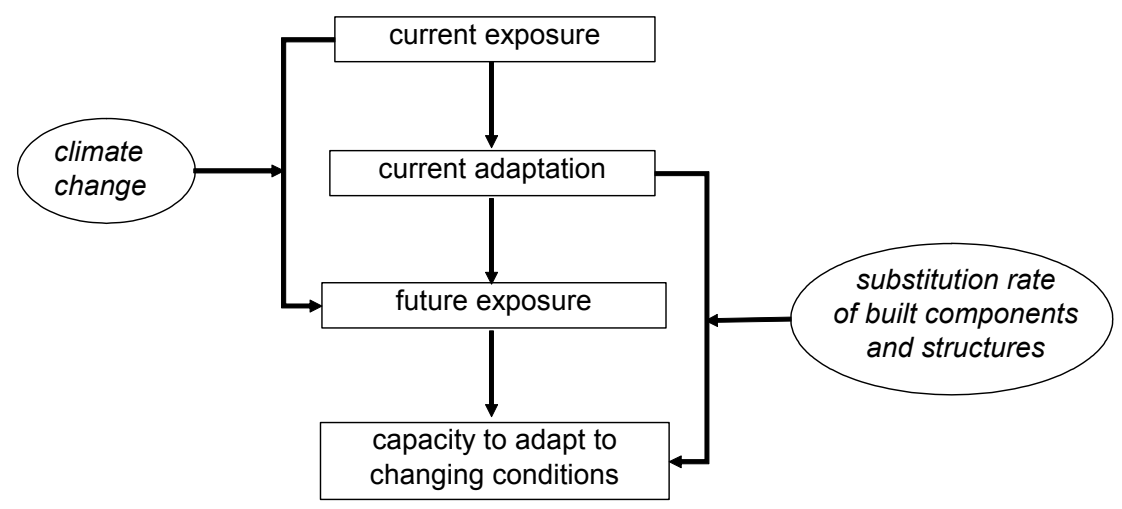

Figure 1: Adapting to climate change: substitution of built components and structures.

All attributes of the urban fabric require upgrades, major refurbishment and/or complete renewal. Roads need resurfacing every 5-10 years, dams and water supply infrastructure need major refurbishment every 20-30 years. Buildings have lifetimes ranging from 30 to 300 years, but exterior surfaces (skin) now change every 20 years and electrical wiring, plumbing and heating systems (services) are replaced every 7 to 15 years. Although cities have always adapted to changing environmental conditions through autonomous adaptation, the dynamics of climate change may warrant to adapting the building stock to better cope with increasing flood risk through planned retrofitting and/or redesigning its structure during its lifetime. A hurtle to move to planned adaptation seems to be the paradox in present day planning practices: a timeframe of 20 years or even less is considered long-term whereas implicitly is assumed that buildings last forever and 'site or urban location is eternal'. 
Planning decisions are thus typically based on specifications that assume that climate is static. In this paper it is argued that renewal schemes of buildings may provide an opportunity to exploit substitutions of built components and structures for planned climate change adaptation. In other words: climate change adaptation should become an element in urban renewal schemes and life cycle assessments which in turn calls for planning ahead for up to 100-years. The capacity to adapt to changing conditions depends on their substitution rates as illustrated in Figure 1.

\section{Shearing layers concept}

In the past three decades, it is increasingly recognised that dynamic societies require agile architecture and that the built environment is the product of an ongoing and never ending design process [12-14]. Much theory and practice on the transformation of buildings such as the 'open building concept' have been developed to understand and exploit these dynamics in creating buildings able to provide capacity to changing functional requirements, different urban conditions, standards of use and life-styles. One of the fundaments of the "open building concept" is the principle of distinct Levels of Intervention: a building can be conceived as a collection of several layers of longevity of built components. Parts of a building can be removed and replaced such as the entire façade of a building, revealing a layer that is independent of its structure. According to Duffy [15] a building consists of shearing layers. He distinguishes four layers: shell or structure, services, scenery or layout, and set or mobilia.

From an economic point of view Tempelmans Plat [14] and Tempelmans and Heynick [16] describes a building as an aggregation of stocks services with different life spans. The latter implies that along similar lines as Duffy [15], a building should be deconstructed into separate layers with different life cycles and depreciation rates. In this paper we roughly followed the layered systematic of Tempelmans Plat and distinguish 3 types of layers (see Figure 2): the structural layer of the building (which is referred in this paper as Group C components) which generally has a life span of 50 yrs or more (European context), the space plan, services and skin layer (Group B components) with life spans between 10 and 25 years and the mobilia (Group A components). At a constant price level and without renewal the total economic value of the property (land and building group B $+\mathrm{C}$ components) depreciates continuously down to the level of the land value. It should be noted that on the long term when the lifetime of the building has expired and its value has dropped to zero, the building still may have a positive market value. The latter is strongly influenced by social factors such as the demand for housing. Since the generally observed disparity between the economic value and the market value hampers rational decision making, in this paper we do not take the market value into account. The expected annual flood damage, which may increase due to climate change, will effect the depreciation rate as illustrated in Figure 3.

It follows from the above that the economic value $v_{i, t}$ of a building $i$ at moment $t$ consists of the initial construction costs (i.e. total investments) $v_{0}$ 


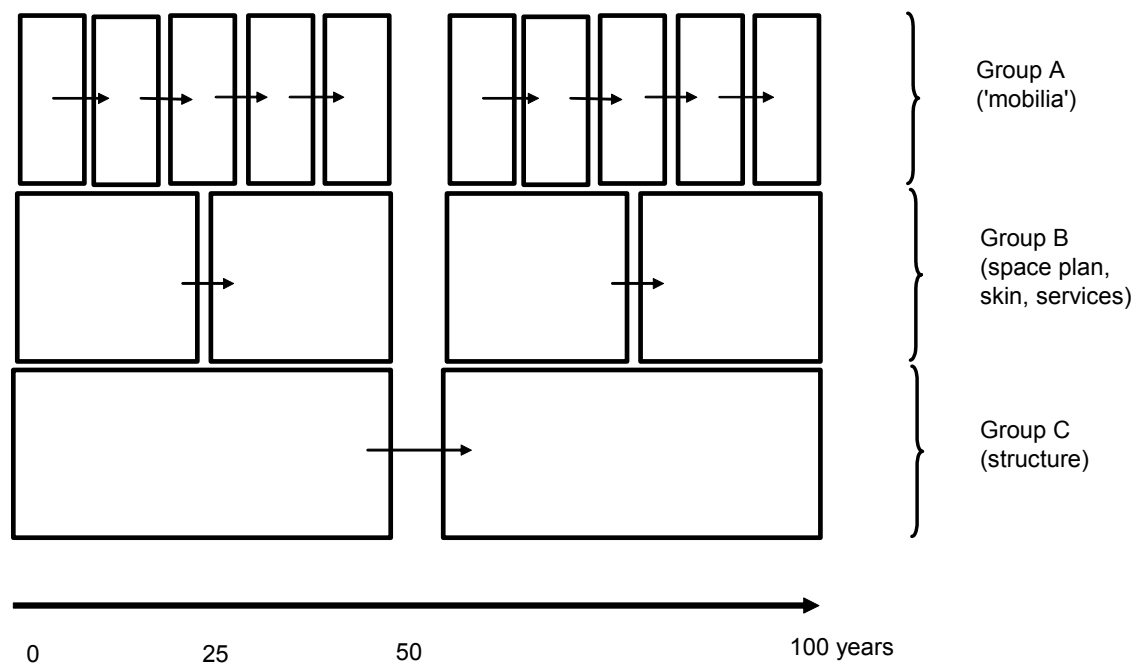

Figure 2: $\quad$ Shearing layers of change (Group A; mobilia, Group B; space plan, services and skin, Group C; structure (new building)) (modified after Duffy [15]).

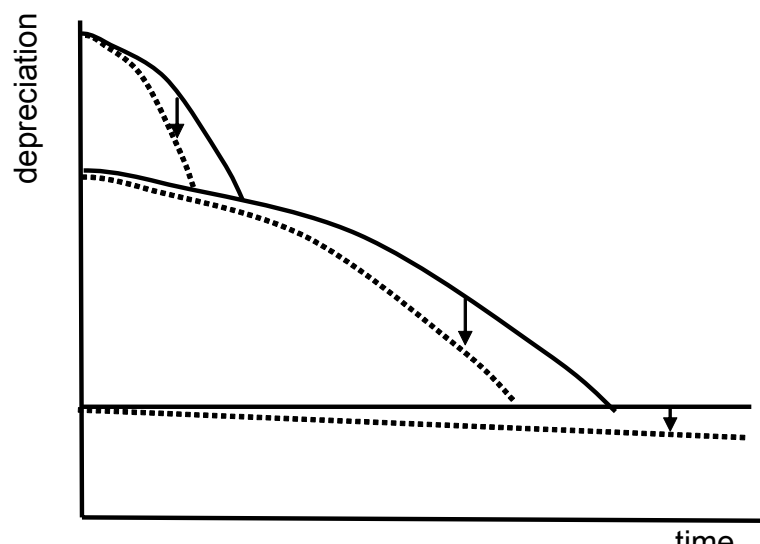

Group B

(space plan, skin, services)

Group C

(structure)

land

Figure 3: Depreciation of a building as an aggregation of layers with (dashed line) and without (solid line) climate change (modified after Tempelmans Plat [14]).

minus the loss of value through depreciation $\alpha_{i, t}$ and the expected flood damage $d_{i, t}$ of a building $i$ at moment $t$ :

$$
v_{i, t}=v_{0} \alpha_{i, t}-d_{i, t}
$$

The depreciation rate is reduced by replacement of built components including those interventions that enhance the flood resilience and/or resistance 
of the building as a whole (non-identical replacement may even increase building's value in the case more valuable components are replaced be less valuable ones). To make depreciation independent from replacement, an additional factor $r_{i}$ is introduced which expresses the added value at the moment new investments are made:

$$
v_{i, t}=v_{0} \alpha_{i, t}-d_{i, t}+r_{i}
$$

\section{Pro-active retrofitting: some theory on timing}

If we define the expected accumulated flood damages $D_{i, t}$ for building $i$ at moment $t$ as the sum of the already accumulated damages and the expected damages, this can be expressed in the following equation:

$$
D_{i, t}=\left(\sum_{j=t 0}^{t_{c}} d_{i, j}+\sum_{j=t_{c}}^{t} f\left(d_{i, j}^{\prime}\right)\right)
$$

where $d_{i, \mathrm{j}}$ are the accumulated damages until the current year $t_{c}$ for years $j$ and $f\left(d_{i, j}^{\prime}\right)$ is the flood damage function until the future year $t$. When retrofitting is applied, the damage function $f\left(d_{i, j}^{\prime}\right)$ is replaced by a new function $f^{\prime}\left(d_{i, j}^{\prime}\right)$ which results in lower levels of expected flood damages. Yet, the level of reduction is depended on the investments made for retrofitting $r_{i}$. The resulting damage reduction $\Delta D_{i, t}$ thus becomes:

$$
\Delta D_{i, t}=\left(\sum_{j=t c}^{t} f\left(d_{i, j}\right)-\sum_{j=t_{c}}^{t} f^{\prime}\left(d_{i, j}^{\prime}\right)+r_{i}\right)
$$

As already mentioned, the costs for retrofitting can be substantially lower when applied during 'normal renewal'. Yet, since the lifespan of layers differ, retrofitting opportunities can coincide with these different renewal moments. The replacement of built components (Group B) can for instance be delayed until the moment major adjustments (Group C) are to be made. Apart from extending the lifespan of the components, new opportunities for flood proofing can be expected when both layers are replaced at the same moment. This decision depends strongly on the damage reduction achieved by these different retrofitting options and the costs that are involved to apply them. If the damage reduction (see equation 4) achieved by replacement of built components at the shorter period for renewal (Group B) is larger than the damage reduction achieved at the later period (Group C), the following holds:

$$
\Delta D_{i, t 1}^{b}>\Delta D_{i, t 2}^{b^{\prime}}+\Delta D_{i, t 2}^{c}
$$

where $\Delta D_{i, t 1}^{b}$ represents the damage reduction achieved when retrofitting is applied at the renewal moment for Group B $t 1, \Delta D^{b^{\prime}}{ }_{i, 2}$ represent the damage reduction (including reduced retrofitting costs for group B) when applied at the renewal moment appropriate for Group $\mathrm{C} t 2$ and $\Delta D^{c}{ }_{i, t 2}$ represents the damage reduction of group $\mathrm{C}$. Note that the damage reduction is strongly depended on 
the costs of retrofitting (see equation 4). Consequently, when the damage reduction achieved by 'early retrofitting' is less or equal than achieved by combining retrofitting for Group $\mathrm{B}$ and $\mathrm{C}$, the following holds:

$$
\Delta D_{i, t 1}^{b} \leq \Delta D^{b^{\prime}}{ }_{i, t 2}+\Delta D_{i, t 2}^{c}
$$

The framework shown above is of course a simplification of the complex nature of the relation between flood damages and retrofitting. Furthermore, many factors involved are characterized by a large level of uncertainty. This includes uncertainties about expected flood damages (e.g. arisen from uncertainties associated with modelling climate variability and change), market factors, innovation and cost reduction in retrofitting technologies, etc. Furthermore, other factors might dominate decisions about renewal like already mentioned changes in functional requirements, building codes, etc.

\section{Deciding when to undertake pro-active retrofitting}

There are three kinds of strategies for dealing with flood events that may be taken at property level. These are:

1. Pro-active retrofitting (i.e. planned retrofitting and/or re-designing to improve property resistance or resilience);

2. Do-nothing + reactive retrofitting (i.e. replacement or repair incorporating resistance or resilience solutions up to flood level);

3. Do-nothing + straight replacement or repair with no resistance or resilience solutions taken (i.e. replacing like for like).

Useful research has been conducted in the field of post-flood restoration or repair of property components with flood resistance or resilience solutions (referred in this paper as 'reactive retrofitting') [17] and of flood proofing of new buildings [18]. Post-flood restoration generally comprises dry proofing the building by sealing or shielding, or wet proofing the building. For new buildings a wider spectrum of solutions is available ranging from minor adjustments to constructions and/or lay-outs to using elevated configurations and floating or amphibious solutions. The latter two categories are however still in an early stage of development and their implementation is largely restricted to a few projects in The Netherlands. Recently, this scientific work has resulted in the translation into guidelines and standards for repair techniques and new buildings $[19,20]$. However, very limited scientific work has been devoted to pro-active retrofitting.

If a pro-active strategy is aimed for, often a decision will need to be made on whether to undertake flood proofing measures now or at some future point in time during the 'normal' renewal scheme of the property (or to do nothing). It is arguable that considerable cost savings are possible if retrofitting is combined with 'normal' renewal, Figure 4. Two main momenta can be distinguished to improve the resistance or resilience of buildings, namely the replacement of structure (Group C) $\rightarrow$ major adjustments, and the substitution of built components (Group B) $\rightarrow$ minor adjustments. In this sense, the type of appropriate flood proofing measure strongly depends on the type of renewal 
action: group B or C. The structural components (Group C) are important for resistance measures where the floodwaters are prevented from penetrating the property. Resilience measures that can be carried out inside the property to minimize the damage caused by floodwaters entering the building may be combined with the replacement of shell components (Group B).

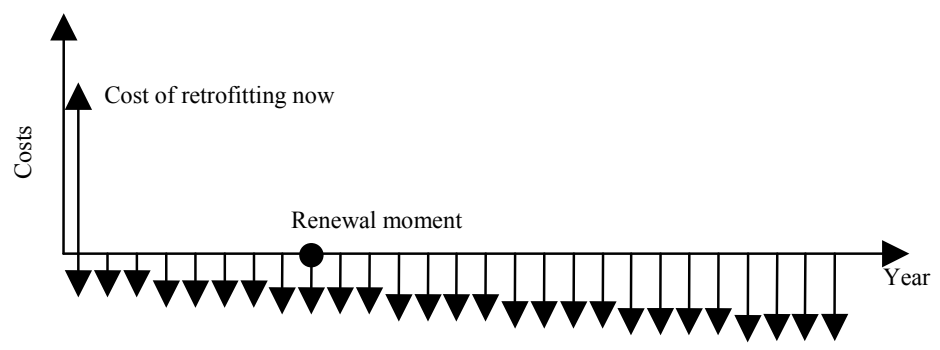

Avoided annual damages

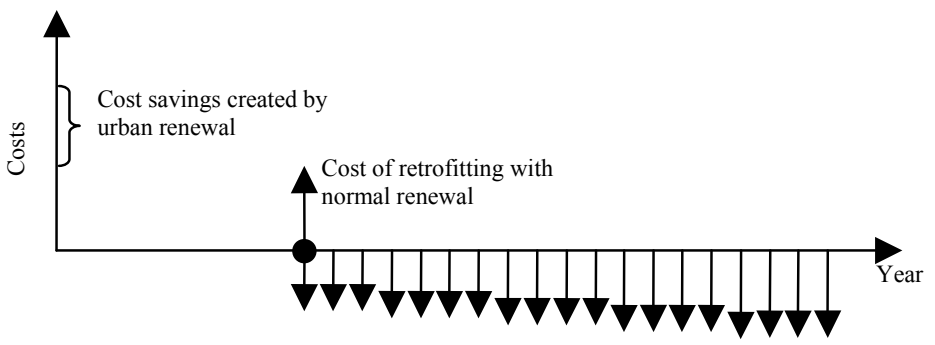

Avoided annual damages

Figure 4: Life cycle cost for the two pro-active retrofitting strategies.

In order to identify when pro-active retrofitting would be best, a benefit-cost analysis should be applied to the two strategies. The following section therefore analyses the benefits and costs of different investment timings for managing flood risks proactively through the use of retrofitting at the property level. Here, two types of measures that may be taken were analyzed, wet proofing until $1.0 \mathrm{~m}$ and permanent dry proofing until $0.9 \mathrm{~m}$ by sealing.

The costs to implement these flood proofing measures are given below for a terraced property (Table 1).

Table 1: $\quad$ Cost to implement building precautionary measures [18].

\begin{tabular}{|l|l|}
\hline Mitigation measure & Cost [euro] \\
\hline Wet proofing & 17,700 \\
\hline Permanent dry proofing & 7,600 \\
\hline
\end{tabular}

Figure 5 shows the effectiveness of the two measures to reduce flood damages. The benefit for the damage reduction strategy is calculated by estimating the difference in expected annual losses compared to the traditional 
way of building. Annual flood damage is computed as the integral of the damage-probability function:

$$
E(S)=\int S(x) d P(x)
$$

where $E(S)$ is the expected annual damage, $S(x)$ is the flood damage caused by flood depth $x$, and $P(x)$ is the probability of flood level $x$.

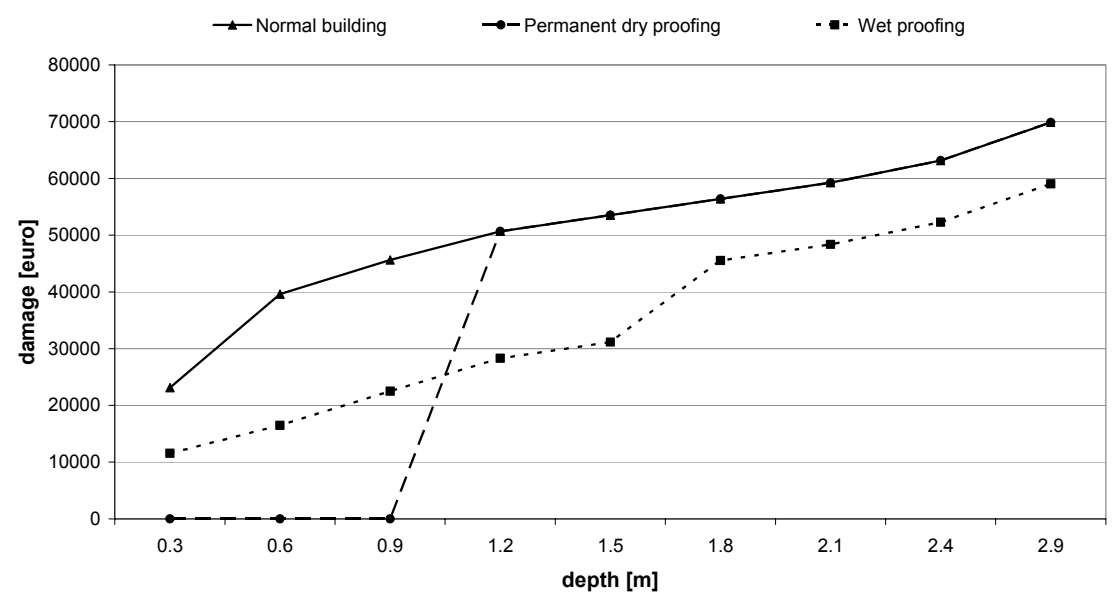

Figure 5: Flood damage curves for terraced property with and without flood proofing measures undertaken [18].

For a case study of a floodplain in Dordrecht [18], the Netherlands, the benefit-cost ratio of the two strategies has been computed: retrofitting 'now' and retrofitting 'with normal renewal'. For this specific regeneration site (built in 1982), the exceedance probability of local water levels was simulated using the probabilistic model Hydra-B [21]. The simulation was done for the present situation as well as for the year 2050 and 2100 in order to assess the impact of climate change and sea level rise on event probabilities.

A benefit-cost analysis has been undertaken over a time horizon of 82 years. The results of this analysis are presented in table 2 for a cost saving of $33 \%$ in case of retrofitting at some future point during 'normal' renewal, and for a discount factor of $3 \%$. These data show that pro-active retrofitting is generally economically worthwhile, with the exception of wet proofing the building 'now'. The benefit-cost ratios indicate that permanent dry proofing is the preferred option. The best investment timing strategy is 'with normal renewal'.

Table 2: $\quad \mathrm{B} / \mathrm{C}$ ratios for different options and retrofitting strategies.

\begin{tabular}{|l|l|l|l|l|}
\hline & \multicolumn{2}{|l|}{ Wet proofing } & \multicolumn{2}{l|}{ Dry proofing } \\
\hline Implementation timing & Now & Year 7 & Now & Year 32 \\
\hline PV flood damages avoided & $€ 17,300$ & $€ 16,000$ & $€ 35,300$ & $€ 22,200$ \\
\hline PV implementation costs & $€ 25,000$ & $€ 6,500$ & $€ 10,400$ & $€ 2,700$ \\
\hline Benefit-cost ratio & 0.7 & 2.5 & 3.4 & 8.2 \\
\hline
\end{tabular}


From a further level of sensitivity testing (Figures 6 and 7) it emerges that the conclusion that pro-active retrofitting 'with normal renewal' is preferred over retrofitting 'now' is not particularly sensitive to changes in the cost savings or discount rate. Only for very low expected cost savings and discount rates does the relative importance of the two strategies become fuzzy for this particular case study.

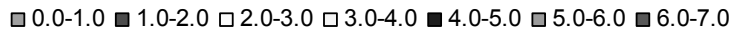

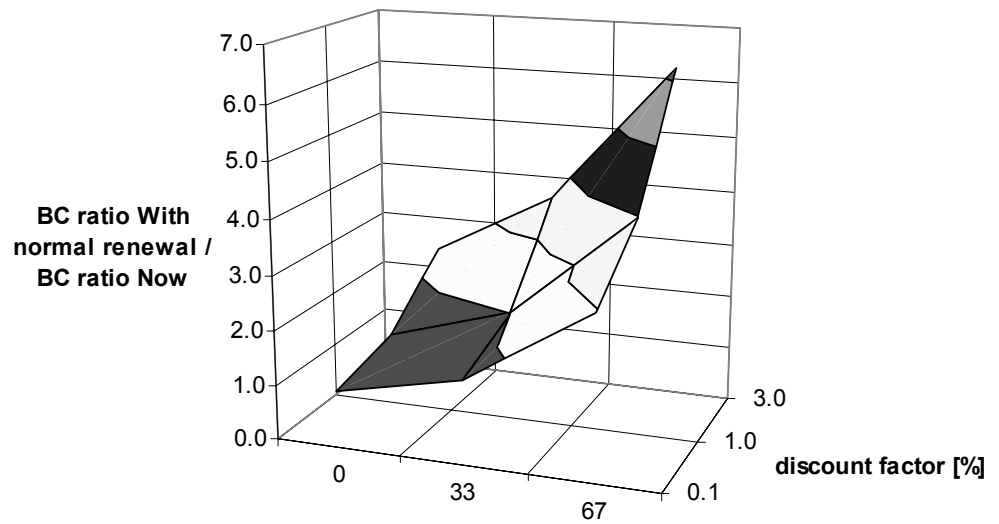

Cost savings of retrofitting With normal renewal [\%]

Figure 6: Efficiency of retrofitting 'with normal renewal' compared to retrofitting 'now' for wet proofing.

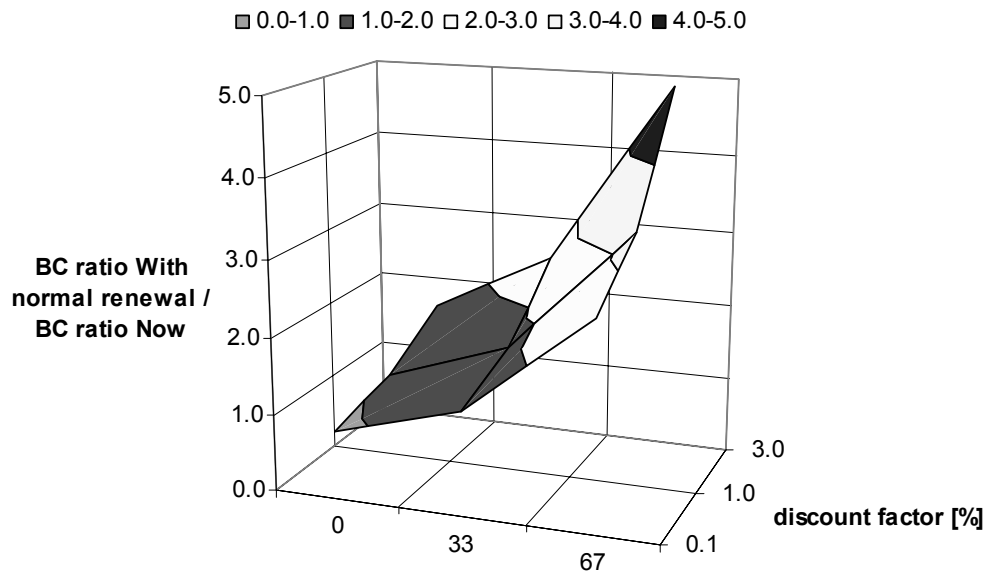

Cost savings of retrofitting With normal renewal [\%]

Figure 7: Efficiency of retrofitting 'with normal renewal' compared to retrofitting 'now' for permanent dry proofing. 


\section{Decision makers and barriers to pro-active retrofitting}

Decision-making for at-risk properties is a complex process and in many cases involves both rational and emotional dimensions. The translation of technical research and planning into policy and practice remains a key challenge. The main actors involved in this translation and decision making on retrofitting and the main barriers they face are highlighted briefly.

Policy makers generally have a short-term objective related to their term of office, whereas retrofitting and renewal policy requires a more long-term perspective and would thus involve several generations of policy makers. On the short term and especially for local policy makers responsible for local policies to retrofit specific urban areas it is hard to obtain (political) benefits unless it is combined with other investments ('package deals') in that area. National policy makers, on the contrary, could provide the policy and legal framework to create incentives for retrofitting.

End-users such as house owners might also have a too short-term perspective and the awareness of flood risk and technical value depreciation might be limited. Especially in the Netherlands house owners expect government to reduce the flood hazard and focus on the market value of their property. Even housing corporations have stated they have stopped writing off their properties as market value is generally increasing.

Real estate developers and contractors are traditionally more focussed on new developments, although this is steady shifting more towards redevelopment, retrofitting, renovation and maintenance. The aging of the current building stock and the reducing green field development opportunities are contributing to this. Also, these private actors are becoming increasing, yet slowly aware of water and flood risk management as business opportunity. Nevertheless, large-scale market uptake of pro-active retrofitting and the development of related technical innovations would benefit greatly from incentives for their clients (house owners).

Given the brief stakeholder analysis above, various steering instruments deserve further research. An interesting range of policy solutions are related to the climate or flood proof certification of developments, redevelopments and retrofitting of individual constructions. High level (e.g. national) policy makers could provide such framework that could be accompanied by subsidies to further stimulate its rapid implementation. Furthermore authorities could be launching customers and the retrofitting of public buildings would serve as demonstration projects. The involvement of the insurance and certification industry would be crucial for further market uptake, e.g. through reduced insurance premiums for certified developments and constructions. Countries such as the United Kingdom are already developing relevant experience and similar policies on the stimulation of eco- or energy efficient construction could serve as an example.

\section{Conclusions}

Traditional buildings are designed based on the assumption that their environments will never experience significant change. However, the dynamics 
of climate change may warrant adaption the building stock in order to accommodate the projected increasing flood risk within a building's lifetime.

This paper explicitly addresses longevity and present value of assets as potential key indicators to assess climate change adaptability of the urban fabric. It provides evidence that depreciation rates of buildings could be significantly affected by projected impacts of climate change and thus should incorporate potential damage increase due to these changes. Consequently, additional investments required for pro-active flood resilient retrofitting should be based on life cycle costs and include potential benefits arisen from reduced potential flood damage. Based on rough estimations the results of this study indicate that regular urban renewal schemes combined with flood proofing reconstruction and retrofitting operations could provide an opportunity to cost effectively adapt a proportion of European's building stock to changing flood risk due to climate change. However, further methodological research is warranted to substantiate these claims and it's application.

This paper also highlights multiple barriers faced by policy makers, house owners and developers that could hamper the practical implementation and large scale market uptake of pro-active flood resilient regeneration or retrofitting. Possible policy instruments and market mechanism that can overcome these barriers require further study. For example, governments could provide the policy and legal framework to create incentives for retrofitting, e.g. climate and flood proof certification of (re)developments and constructions.

\section{References}

[1] Barredo, J.I., Lavalle, C., De Roo, A. (2005). European flood risk mapping. European Commission, DG-Joint Research Centre, Ispra, Italy

[2] EEA. (2006). Climate Change and the EU's response. Europa press release. 6th November 2006 (MEMO/06/406).

[3] Ashley R. (2006). The future for water and flood risk management in highly susceptible urban areas; 9th Inter-Regional Conference on Environment-Water, EnviroWater 2006, Delft, the Netherlands.

[4] EEA. (2005). Climate change and river flooding in Europe. EEA Briefing 2005/01, European Environment Agency, Copenhagen.

[5] Commission of the European Communities (2006). Proposal for a Directive of the European Parliament and of the Council on the assessment and management of floods $\{\operatorname{SEC}(2006) 66\}$. Brussels, 18.01.2006 COM (2006) 15 final 2006/2005 (COD).

[6] European Construction Technology Platform (ECTP) (2005). Strategic Research Agenda for the European Construction Sector.

[7] FORESIGHT (2005). Foresight Flood and Coastal Defence Project, http://www.foresight.gov.uk/index.html

[8] ABI (2005). Making communities sustainable. February

[9] Pahl-Wostl C., Downing T., Kabat P., Magnuszewski P., Meigh J., Schlueter M., Sendzimir J., and Werners S. (2005). Transition to Adaptive Water Management; The NeWater project. Water Policy. NeWater 
Working Paper X., Institute of Environmental Systems Research, University of Osnabrücklimate change and river flooding in Europe. EEA Briefing 2005/01, European Environment Agency, Copenhagen..

[10] Pahl-Wostl C., Möltgen J., Sendzimir J., Kabat P. (2005). New methods for adaptive water management under uncertainty - The NeWater project. Paper accepted for the EWRA 2005 conference.

[11] Veerbeek W., Zevenbergen C., Gersonius B. and Herk S. van (2008). Increasing flood resilience: defining constraints for a mixed strategy approach by using a fine grain damage model. Submitted to Journal of Flood Risk Management.

[12] Brand, S. (1994). How Buildings Learn: What Happens After They Are Built. New York: Viking.

[13] Prins, M., T. Bax, J.C. Carp, and H. Templemans Plat. (1993). "A Design Decision Support System for Building Flexibility and Costs.” Design and Decision Support Systems in Architecture and Urban Planning. Netherlands: Kluwer Academic Publishers.

[14] Templemans Plat, H. (1990). "Towards a Flexible Stock of Buildings: The problem of cost calculations for buildings in the long run." Proceedings, CIB World Congress, New Zealand.

[15] Duffy, F. (1990). Measuring Building Performance. Facilities, May, p. 17

[16] Tempelmans Plat, H., Heynick, F. (2002). Economics of property management. ISBN10: 0750651237. $208 \mathrm{pp}$.

[17] ABI. (2002). Assessment of the cost and effect on future claims of installing flood damage resistant measures.

[18] Gersonius, B, Zevenbergen, C., Puyan, N., and Billah, M. (2008). Efficiency of private flood proofing of new buildings - Adapted redevelopment of a floodplain in the Netherlands. FRIAR 2008, this volume.

[19] Bowker, P., Escarameia M., Tagg A. (2007). Improving the Flood Resilience of Buildings through Improved Materials, Methods and Details, CIRIA, London. .

[20] Garvin, S., Reid, J. and Scott, M. (2005). Standards for the repair of buildings following flood. CIRIA, London, UK.

[21] Duits, M., (2004). Gebruikershandleiding Hydra-B (3.1 ed.), HKV LIJN IN WATER, Lelystad. 